Scholars International Journal of Biochemistry

Abbreviated Key Title: Sch Int J Biochem ISSN 2616-8650 (Print) |ISSN 2617-3476 (Online) Scholars Middle East Publishers, Dubai, United Arab Emirates Journal homepage: https://scholarsmepub.com/sijb/

Review Article

\title{
A Novel Approach towards Nutraceuticals and Biomedical Applications
}

\author{
Usman Ghani ${ }^{1}$, Muhammad Naeem ${ }^{1 *}$, Hamza Rafeeq ${ }^{1}$, Usman Imtiaz ${ }^{1}$, Ayesha Amjad ${ }^{1}$, Saqib Ullah ${ }^{1}$, Asim Rehman ${ }^{2}$, \\ Fatima Qasim ${ }^{1}$
}

${ }^{1}$ Department of Biochemistry, University of Agriculture, Faisalabad, 38000, Pakistan

${ }^{2}$ Department of Biochemistry, Govt. College University Faisalabad, 38000, Pakistan

\begin{abstract}
DOI: $10.36348 /$ SIJB.2019.v02i10.001
| Received: 15.10.2019 | Accepted: 22.10.2019| Published: 27.10.2019
\end{abstract}

*Corresponding author: Muhammad Naeem

\section{Abstract}

Nutraceuticals is a broad term derived from nutrition and pharmaceutical. Nutraceuticals are used as a part of food for preventing and treating many acute and chronic diseases. Nutraceuticals are divided into three main categories including herbs, nutrients and dietary supplements. The food products which are used as nutraceuticals are dietary fibers, prebiotics, probiotics, polyunsaturated fatty acids, antioxidants, spices and some other types of types of herbs and natural foods. Probiotics are ingested for their positive advantages in the digestive tract or systemic area like in the liver, brain, vagina or blood stream. Antioxidants are essential for treatment of almost all diseases because most chronic diseases occur due to oxidative stress. Flavonoids and phytochemicals have antioxidant properties due to which it act as therapeutic agents for various diseases such as anti-cancerous.Omega-3 polyunsaturated fatty acids are used for lowering the high levels of cholesterol in cardiovascular diseases and many inflammatory diseases.

Keywords: Nutraceuticals, Prebiotics, Probiotics, Antioxidants, Vitamins, Diabetes.

Copyright @ 2019: This is an open-access article distributed under the terms of the Creative Commons Attribution license which permits unrestricted
use, distribution, and reproduction in any medium for non-commercial use (NonCommercial, or CC-BY-NC) provided the original author and source
are credited.

\section{INTRODUCTION}

In 1989 Stephen Defelice discovered a word nutraceutical which is derived from two words pharmaceuticals and nutrition. He was the chairman of an American organization known as Foundation for Innovation in Medicine (FIM) which encourages the medical health. Defelice explained the word nutraceutical as that portion of food which have beneficial effects about our health and also have therapeutic uses. Due to these benefits nutraceuticals are used for inhibition and cure of many disorders. The nutraceutical products are extracted from different sources such as herbal products, different supplements extracted from diets and nutrients and some diets are formed by gene modifications [16].

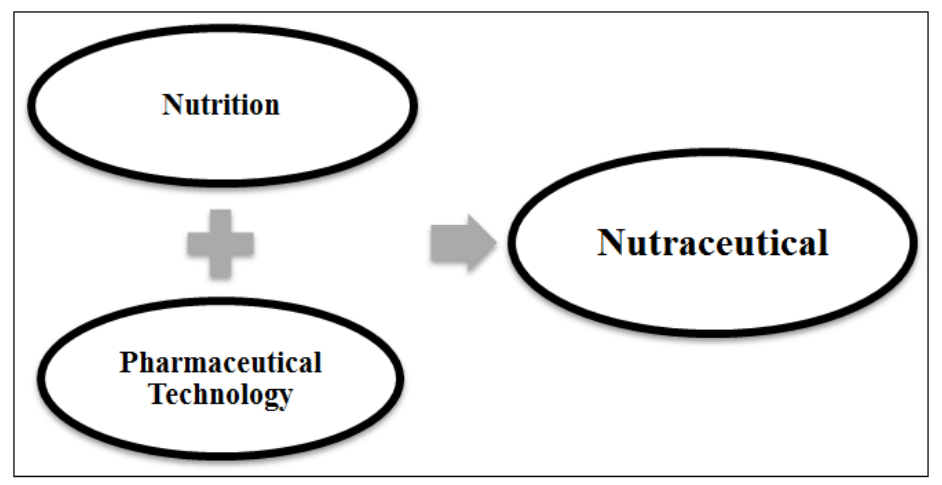

Fig-1: Formulation of Nutraceuticals

There are various varieties of plants that produce compounds like alkaloids and these compounds are used by humans in prevention from different infections and these compounds are also used for the treatment of many diseases in human beings. In ancient times plants are used for the treatment of many diseases so the ancient history is helpful in finding the properties and activities of different plants. 
These nutraceuticals have an important role in different functions of our body and are also useful in lowering the risk of many diseases in humans. These pharmaceutical foods are used for the cure and prevention of many diseases, to develop immunity in body and to manage health. According to recent research it has been scientifically proved that these nutraceuticals are very efficient in preventing and curing many disease situations [44]. Nutraceuticals can be used as therapeutic agents for various diseases such as cardiovascular diseases, cancer, obesity, diabetes mellitus, osteoporosis, depression, for lowering cholesterol levels, for cure of many disorders related to sleep and also for osteoarthritis.

\section{MAIN CATEGORIES OF NUTRACEUTICALS}

Nutraceuticals are wide variety of biological treatments which are used to improve the quality of life, to regulate the signs and symptoms of many diseases and to inhibit many disease related processes. The nutraceuticals can be divided into three major categories including herbals, nutrients and dietary supplements.

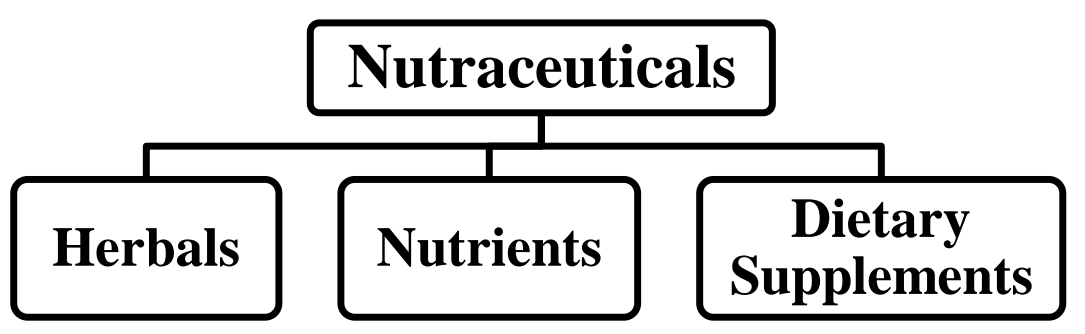

Fig-2: Categories of nutraceuticals

There are many products of herbs which are extracted from different herbs. Garlic, wheat grass, aloe vera, and ginger are some natural plant sources which are used as herbals. Nutrients are the compounds which are present in our diets naturally such as fatty acids, vitamins, amino acids and many carbohydrates. Dietary supplements are the substances which are extracted from different food sources and used for performing specific role or function in human body [2].

\section{Herbals}

Herbals are the products which are obtained by isolating them from many plant sources. In old times humans used these herbal products as medicine for the cure and prevention of many biological disorders. The information about the herbal products can be obtained from ancient history and proves very beneficial to improve the quality of life [37]. Nutraceuticals play an important role in improving health and prevent chronic diseases with the help of herbals.

Table-1: Herbals and their health benefits

\begin{tabular}{|c|c|c|}
\hline Herbals & Therapeutic relevance & References \\
\hline $\begin{array}{l}\text { Aloe Vera gel } \\
\text { (Aloe Vera L. N.L.Burm.) }\end{array}$ & $\begin{array}{l}\text { Dilate capillaries, emollient, anti-inflammatory and } \\
\text { wound healing properties. }\end{array}$ & {$[34]$} \\
\hline $\begin{array}{l}\text { Lavender } \\
\text { (Lavandulaangustifolia) }\end{array}$ & $\begin{array}{l}\text { Contains tannin for curing depression, hypertension, } \\
\text { stress cold, cough and asthma. }\end{array}$ & {$[43]$} \\
\hline $\begin{array}{l}\text { Garlic } \\
\text { sativum L.). }\end{array}$ & $\begin{array}{l}\text { Antibacterial, antithrombotic, anti-inflammatory and } \\
\text { antifungal activity. }\end{array}$ & [30] \\
\hline $\begin{array}{l}\text { Ginger } \\
\text { (ZingiberofficinaleRosc.) }\end{array}$ & $\begin{array}{l}\text { Antiemetic, carminative, antioxidant properties to } \\
\text { reduce oxidative stress, inhibit lipid peroxidation, } \\
\text { prevent microbial food spoilage. }\end{array}$ & {$[15]$} \\
\hline $\begin{array}{l}\text { Willow bark } \\
\text { (Salix nigra) }\end{array}$ & $\begin{array}{l}\text { Salicin is an anti-inflammatory, analgesic, antipyretic, } \\
\text { astringent and antiarthritic. }\end{array}$ & [32] \\
\hline $\begin{array}{l}\text { Parsley } \\
\text { (Petroselinumcripsum) }\end{array}$ & $\begin{array}{l}\text { Contain flavonoid (apiol) and is diuretic, and used in } \\
\text { flavoring and aromatic food additives. }\end{array}$ & {$[28]$} \\
\hline
\end{tabular}

\section{Nutrients}

Nutrients are the compounds which are present in our diets naturally with recognized nutritional standards such as minerals vitamins fatty acids and polysaccharides. Many natural food sources such as fruits, dairy products, vegetables meat of chicken contain all the essential nutrients of our diet. Due to this these nutrients are used for the treatment and prevention of many diseases such as cardiovascular diseases, diabetes mellitus, different types of cancer, osteoporosis, obesity and osteoarthritis [20].These nutrients contain many minerals, antioxidants, fat and water soluble vitamins which are taken from our diet and are beneficial for many of our health problems. More consumption of vitamin $\mathrm{E}$ in our diet can be used for the cure of Parkinson's disease. Many antioxidants are used for the treatment of many cardiovascular diseases and various types of cancers. Vitamin $\mathrm{C}$ in its 
oxidized form like in dehydroascorbic acid can pass through the blood brain barrier quickly. Recent studies shows that high intake of antioxidants in our diet can be used for the cure of Alzheimers disease. If these vitamins such as vitamin $\mathrm{C}, \mathrm{E}$ and beta carotenes can be used for reducing the oxidation amount of low density lipoprotein [27].

Supplementation of vitamins is also related to vaccines of tetanus and hepatitis $B$ which increases the amount of antibodies. Cancer of pancreas is due to the low level of selenium in the serum so if selenium is used in the form of supplements in our diet it can reduce the risk of cancer. Enzymes which are used in metabolism, curing of wounds and in the process of digestion contain zinc as an essential component. For the synthesis of nitric oxide arginine is an important amino acid. The additives of arginine can increase the capability of exercise in persons who are suffering from angina. There are many common nutrients with their health benefits [4].

Table-2: Nutrients and their health benefits

\begin{tabular}{|l|l|l|}
\hline Nutrients & Health benefit & References \\
\hline Vitamin A & $\begin{array}{l}\text { Antioxidant, necessary for growth and development, maintain healthy vision, skin } \\
\text { and mucous membranes, help for the prevention and treatment of certain cancers } \\
\text { and skin disorders. }\end{array}$ & {$[43]$} \\
\hline Vitamin D & $\begin{array}{l}\text { Vital for formation of bones and teeth, helps to body absorb and use calcium, } \\
\text { regulate calcium and phosphate absorption. }\end{array}$ & {$[26]$} \\
\hline Vitamin E & $\begin{array}{l}\text { Antioxidant, helps in forming blood cells, muscles, lung and nerve tissue, boosts the } \\
\text { immune system. }\end{array}$ & {$[24]$} \\
\hline Vitamin K & Essential for clotting of blood. & {$[43]$} \\
\hline Vitamin C & $\begin{array}{l}\text { Antioxidant, anti-inflammatory nutrient, important in wound healing and prevent } \\
\text { common cold. }\end{array}$ & {$[40]$} \\
\hline Vitamin B1 & Helps inconvertion of food into energy and essential in neurologic functions. & {$[21]$} \\
\hline Vitamin B2 & $\begin{array}{l}\text { Helps in production of energy and other chemical processes in the body, helps in } \\
\text { maintaining healthy eyes, skin and nerve function. }\end{array}$ & {$[21]$} \\
\hline Vitamin B3 & Helps to convert food into energy and maintain proper brain functioning. & {$[4]$} \\
\hline Vitamin B12 & $\begin{array}{l}\text { Helps to produce the genetic material of cells, helps in formation of red blood cells, } \\
\text { maintenance of central nervous system and synthesize amino acids and is involved } \\
\text { in metabolism of fats, protein and carbohydrates }\end{array}$ & {$[25]$} \\
\hline Folic acid & $\begin{array}{l}\text { Produce the genetic materials of cells, essential in first three months of pregnancy } \\
\text { for preventing birth defects, RBCs formation, protects against heart disease. }\end{array}$ & {$[7]$} \\
\hline
\end{tabular}

Minerals are present in animal meat, plant products and milk products which are important for the treatment of many diseases such as anemia and osteoporosis. These are also used in formation of teeth, skeleton and many muscles. These minerals are also used to regulate the heart beat and pulse rate. Polyunsaturated fatty acids are present in seeds of flax have regulate the inflammatory response and also regulate the functions of brain [33].

Table-3: Minerals and their health benefits

\begin{tabular}{|l|l|l|}
\hline Minerals & Health Benefits & References \\
\hline Calcium & $\begin{array}{l}\text { Essential for building bones and teeth and maintaining bone strength, important } \\
\text { in nerve, muscle and glandular functions. }\end{array}$ & {$[35]$} \\
\hline Iron & Helps in energy production, helps to carry and transfer oxygen to tissues. & {$[4]$} \\
\hline Magnesium & $\begin{array}{l}\text { Essential for healthy nerve and muscle function and bone formation, may help } \\
\text { prevent premenstrual syndrome (PMS). }\end{array}$ & {$[17]$} \\
\hline Phosphorous & $\begin{array}{l}\text { Essential for building strong bones and teeth, helps in formation of genetic } \\
\text { material, energy production and storage. }\end{array}$ & {$[4]$} \\
\hline Zinc & $\begin{array}{l}\text { Essential for cell reproduction, normal growth and development in children, } \\
\text { wound healing, production of sperm and testosterone }\end{array}$ & {$[41]$} \\
\hline
\end{tabular}

\section{Dietary Supplements}

Dietary supplements are the substances which are synthesized by adding some essential constituents in our diet. These dietary supplements are taken in diet. In 1994 through Dietary Supplement Health and Education Act it was explained that dietary supplements are the substances in which some essential constituents like minerals, plant extracts, proteins, and vitamins are incorporated in the food [3].

Many dietary supplements have many therapeutic uses such as glucosamine is used for the treatment of osteoarthritis, black cohosh is used for cure of menopause and ginkgo biloba have beneficial effects 
for the treatment of dementia. Different additives are used in diets used for sports, many supplements are used for lowering the body weight. These dietary supplements are used in different dosage forms like capsules, powders and tablets [13].

Table-4: Dietary supplements and their health benefits

\begin{tabular}{|c|c|c|}
\hline Dietary supplements & Significance & References \\
\hline Ketogenic diets & $\begin{array}{l}\text { Comprised of foods with high fat and low protein and carbohydrate } \\
\text { content, have been reported to improve seizure control. However, } \\
\text { these diets are widely acknowledged to be unpalatable. }\end{array}$ & [13] \\
\hline Minimally refined grains & $\begin{array}{l}\text { Cereals and grains fortified with calcium may reduce the incidence of } \\
\text { diabetes and prevents gastrointestinal cancers. }\end{array}$ & [21] \\
\hline Phytoestrogens & $\begin{array}{l}\text { Found in soya flour and linseeds and have been documented to } \\
\text { enhance estrogens levels when hormonal levels are low. This action } \\
\text { may prevent against both hot flushes and breast cancer. }\end{array}$ & [1] \\
\hline $\begin{array}{l}\text { Several species of edible } \\
\text { mushrooms }\end{array}$ & $\begin{array}{l}\text { Tonnage, Lentinus, Pleurotus, Auricularia, Flammulina, Tremella, } \\
\text { and Grifola have varying degrees of immunomodulatory, lipid } \\
\text { lowering and antitumor without any significant toxicity. }\end{array}$ & {$[36]$} \\
\hline $\begin{array}{l}\text { Glucosamine sulfate and } \\
\text { chondroitin sulfate }\end{array}$ & They are effective and safer to alleviate symptoms of osteoarthritis. & [9] \\
\hline Peptides/Hydrolysates & $\begin{array}{l}\text { Found in casein and whey protein and have A.C.E. inhibitor activity. } \\
\text { Buckwheat proteins used as flour reduces cholesterol, hypertension; } \\
\text { improve constipation and obesity by acting similar to dietary fibers } \\
\text { and interrupting the in-vivo metabolism. }\end{array}$ & [22] \\
\hline Dairy foods & $\begin{array}{l}\text { Containing friendly or probiotic bacteria claimed to promote gut } \\
\text { health. Bio yoghurts containing Lactobacillus acidophilus and } \\
\text { Bifidobacteria lead the sector. }\end{array}$ & [3] \\
\hline
\end{tabular}

Natural food sources used as nutraceuticals

Different natural foods are used as nutraceuticals and they are divided into many categories on the bases of their mode of their activity and the nature of their constituents. The food sources used as nutraceuticals can be categorized as dietary fibres, probiotics, prebiotics, polyunsaturated fatty acids, vitamins, antioxidants and spices.

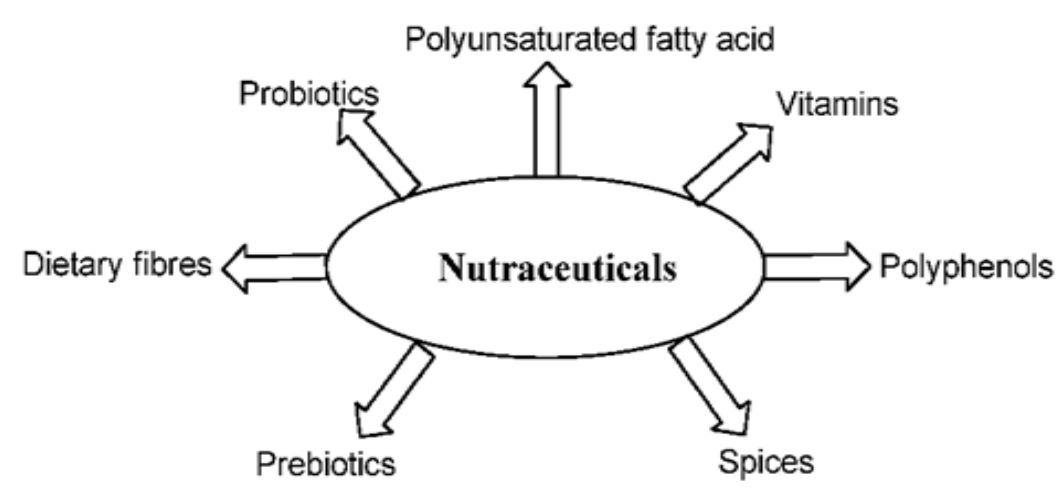

Fig-3: Natural food sources as nutraceuticals

\section{Dietary fiber}

Dietary fibers are the most essential part of diet which is beneficial to health. It is the most important element of a healthy diet. With the help of dietary fiber our diet can be digested efficiently and wastes can easily pass via digestive system. These fibers are usually carbohydrate compounds. Dietary fibers are classified into two types including insoluble dietary fibers and soluble dietary fibers. These fibers perform their work in different ways while both these fibers perform bowel function. Many natural food sources contain both types of fibers in different concentrations.

\section{Insoluble dietary fiber}

Insoluble dietary fiber cannot be mixed in water properly and water is attracted towards these fibers in the intestine due to which feaces become bulky. In the digestive tract it also causes the rapid passage of food ingredients. Hence, insoluble fiber also helps to avoid from symptoms like constipation cancers of colon and diverticular disorders. These fibers constitute the rigid and rubber like portion of many vegetables and grains.

\section{Soluble dietary fiber}

Soluble dietaryfiber can be mixed in water easily. These fibers decrease the process of passage of 
food through our body due to which feaces cannot form bulky. Soluble fibers also regulate the levels of cholesterol in our body and also regulate the level of sugar in blood of patients suffering from diabetes. It also helps to maintain and cure the blood pressure. Pectins and gums are present in fruits, vegetables, and beans are examples of these dietary fibers.

\section{Probiotics}

Probiotics are the food compounds that are composed of live microbes and these compounds have many beneficial effects on human body. When these probiotic feed supplements are taken in suitable concentrations are very beneficial for the host by maintaining the microbial stability in the intestine. These probiotics are used as food supplements and have many beneficial effects in the digestive tract and in many organs like brain, blood stream and liver [10]. There are various types of bacterial species which have the probiotics properties such as including Bifidobacteriumlactis, Streptococcus and Lactococcus species. These probiotic species of different bacteria have antimicrobial properties that fight with bad bacteria to attach with gut wall. These bacteria also fight for nutrients and stimulate the immune system which prevents the growth and development of dangerous bacteria. These also increase the function of immune system and also enhance the ability of our body to resist against many diseases and infections [24].

Uptake of these probiotics also reduce the signs and symptoms of many disease condition like asthma, sensitivity reactions and many infections related to urinary tract. It is also beneficial in the treatment of gastrointestinal (GI) infections like diarrhea and intolerance related to lactose. Probiotics usually present in many dosage forms like in the form of gel and capsules. These probiotics have many therapeutic properties against many pathogens and synthesizing many antimicrobial compounds [39].

\section{Prebiotics}

Prebiotics are the dietary constituents that cannot be digested and have many useful effects on our body. In the colon they change the structure and their performing activity of microbiota, motivating the growth and action of very few bacteria which can improve the health of host [11]. There are many food sources like oligosaccharides as well as polysaccharides having prebiotic activity. Dietary fibers have the properties of prebiotics but many carbohydrates have not the properties of prebiotics. Due to this reason these prebiotics are dividing into many classes by creating specific criteria.

According to these classifications these substances have to resist acidity related to gastric, absorption through the gastro intestine, and the enzymes of mammals perform hydrolysis. Micro flora present in the intestine cause fermentation. The effects of prebiotics are also related to the microbiota that has many beneficial effects on the host health. Galacto and fructo oligosaccharides (GOS), (FOS), and pyrodextrins are some common examples of prebiotics [23]. Some prebiotics like FOS are present in high concentrations in some vegetables and fruits like allium, banana, tomato and some in chicory roots. Stachyose and raffinose present in beans also possess the properties of prebiotics. These prebiotics have many beneficial effects on the human host including improvement in tolerant ability related to lactose, can activate the immune system of intestine, lowering the levels of lipids and cholesterol in the blood and also perform activity against tumors [8].

\section{Antioxidants}

Antioxidants are the substances, which prevent damage or destruction which is caused by oxidation.According to the recent research there are many common diseases like cardiovascular diseases, high blood pressure, osteoarthritis, and diabetes which are related to very low level of compounds known as antioxidants in our diet. Due to these reasons antioxidants are an important portion of many nutraceutical products. Free radicals are generated by the process of oxidation and they can damage many tissues by reacting with them. There is a large amount of different types of antioxidants used in nutraceuticals. These antioxidants react against free radicals and neutralize them in very low amount. These antioxidants prevent membranes from damaging by the process of oxidation. There are many vitamins which are present in fruits and vegetables in large amount and act as antioxidants like vitamin $\mathrm{C}$ and $\mathrm{E}$. Due to the antioxidant properties of these vitamins they are used for the cure of diseases like cardiovascular diseases, and cancer which are caused mainly by the oxidative stress [5].

Many of the acute and chronic disorders are mainly caused by the oxidative stress, due to this reason these antioxidants are commonly very important for the cure and prevention of many disorders. Many diseases related to neurons are caused by the destruction of neurons due to oxidative stress like Parkinson's disease (PD), and Alzheimer's disease (AD). According to recent studies high intake of antioxidants in diet is related to the cure of Alzheimer's disease. It is very important to use these antioxidants in our diet because the prevention of biological disorders is better than their cure. These antioxidants are present in many oils extracted from many vegetables like canola oil and oils extracted from Soybean [18].

\section{Polyunsaturated fatty acids (PUFA)}

There are essential amino acids that cannot be produced by human body but are very essential for the normal functioning of the body. Because they are necessary for regulation of many body functions, they are administered by adding them in the diet from 
outside. Polyunsaturated fatty acids are also included in this type of fatty acids [6]. FAs related to a family of naturally occurring polyunsaturated fatty acids (PUFAs) includes fatty acids having omega 3 numbering. Linolenic acid is also an essential fatty acids and it cannot be synthesized in our body due to the lack of basic metabolic paths which are used for the production of long chain fatty acids. Due to this reason these fatty acids are obtained from outside directly by different food sources such as plants produce docosagexanoic acids (DHA) and eicosapentaoic acid (EPA). These polyunsaturated fatty acids can also be obtained from marine sources [29].

Oils obtained from fish, plankton and algae also produce fatty acids with omega 3 bonds such as DHA and EPA. Polyunsaturated fatty acids related to linoleic acid can also be obtained from oils extracted from natural sources like vegetables and marine sources. These PUFAs are very useful for lowering the cholesterol levels in our body. It also prevent from excess accumulation of cholesterol in the body which leads to the formation of thromboxane. Oils extracted from soybean, sunflower and from mustard seeds can be used for this purpose. There are fatty acids that are essential for the formation of many cell membranes may include omega 6 fatty acids and also omega 3 fatty acids.

These fatty acids are also very important for production of many substances that are involved in the regulation of inflammatory reactions and blood pressure in the body. Fatty acids having bonds at omega 6 and omega 3 positions both are important components of cell membranes. Many diseases related to heart can be cured by fatty acids having bonds at omega 3 position and also prevent the inflammatory reactions. According to recent studies fatty acids having omega 3 bonds are also involved for the treatment of cancer and also cure the diabetes mellitus [14]. Due to prohibition and cure of many fatal diseases such as hypertension, diabetes, diseases related to heart, and disorders of immune system, PUFAs are of great importance. These fatty acids are also very important for the regulation of body growth and maintain functions of brain [31].

\section{Spices}

To improve the food quality spices are used that are the food flavors. In many countries wide variety of spices is used in different concentrations. These spices give specific colour and scent to food that increase the food quality and also enhance the appetite. According to recent research the presence of very low amount of spices in our diet have many antiinflammatory and antioxidant properties which play a very important role in maintaining the health. These spices are also very effective in preventing body from many diseases such as disorders of respiratory system, dysfunctioning of neurons, and cardiovascular diseases [19]. There are many important components of spices such as some components of oils and terpenes. These spices have many beneficial effects on the health such as some quantity of garlic is enough for reducing the concentration of cholesterol in the body. According to recent research blood pressure and lipid content can be regulated by the use of garlic in our diet [38].

\section{Flavonoids}

Flavonoids are naturally present in vegetables, fruits and in various plants. These flavonoids are major class of polyphenols related to the plant secondary metabolites and have many beneficial effects to inhibit various types of cancers in humans. Recent studies shows that diets which are rich in flavonoids have many minute chances of different types of cancer such as breast cancer, cancer of colon and prostate. There are various types of flavonoids which are categorized on the bases of their structures such as flavanols, flavones and antocyanins. Flavonoids are involved in the cure of many cancers by inhibiting various mechanisms like it inhibits the progression of cancer cells, initiates the process of apoptosis in cancer cells, it also target many mechanisms related to signaling pathways in cancer cells and also involved in the suppression of tumor angiogenesis [45].

Quercetin is a well-known flavone and it is naturally present in apples and onions abundantly. Quercetin due to its anticancer properties is used for the cure of various types of cancers in humans like in breast cancer, lung cancer, liver cancer, and cancer of cervical and colon [42]. Due to low absorption quercetin normally shows poor oral bioavailability. To avoid from it nanoparticles are used to increase the effect of quercetin. A microencapsulation method is used for the reduction of the oxidative damage and reducing inflammation due to increased absorption [12].

\section{CONCLUSION}

There is important role of nutraceuticals in our daily life to improve the quality of life.Many chronic diseases such as heart diseases and cancer can be cured by using natural food sources such as vegetables, fruits and grains. Isoflavonoids and other such products reduce the concentration of VLDL and increase the concentration of HDL to cure cardiovascular diseases. Consumption of trans, saturated fats, extreme utilization of diets that are rich in energy like drinks, modified foods and snacks are the main causes of gaining weight.

\section{REFERENCES}

1. Bilal, I., Chowdhury, A., Davidson, J., \& Whitehead, S. (2014). Phytoestrogens and prevention of breast cancer: the contentious debate. World journal of clinical oncology, 5(4): 705.

2. Dahiya, K. (2013). Nutraceuticals and their impact on Human Health. Journal of Plant Biochemistry \& Physiology. 
3. Dolkar, D., Bakshi, P., Wali, V. K., Sharma, V., \& Shah, R. A. (2017). Fruits as nutraceuticals. Ecology, Environment and Conservation, 23: 113-118.

4. Dureja, H., Kaushik, D., \& Kumar, V. (2003). Developments in nutraceuticals. Indian journal of pharmacology, 35(6): 363-372.

5. Elliott, J. G. (1999). Application of antioxidant vitamins in foods and beverages. Food Technol., 53: 46-48.

6. Escott-Stump, S., \& Mahan, L. K. (Eds.). (2000). Krause's Food, Nutrition and Diet Therapy. WB Saunders.

7. FanHou, F. (2018). Effect of smoking and folate levels on the efficacy of folic acid therapy in prevention of stroke in hypertensive men. Stroke.

8. Fuller, R. (1992). History and development of probiotics. In Probiotics. Springer, Dordrecht, 18.

9. Gerlie, C., Koda, R. T., \& Lien, E. J. (2000). Glucosamine and chondroitin sulfates in the treatment of osteoarthritis: a survey. In Progress in drug research (pp. 81-103). Birkhäuser, Basel.

10. Gibson, G. R. (2004). Fibre and effects on probiotics (the prebiotic concept). Clinical Nutrition Supplements, 1(2): 25-31.

11. Gibson, G. R., \& Roberfroid, M. B. (1995). Dietary modulation of the human colonic microbiota: introducing the concept of prebiotics. The Journal of nutrition, 125(6): 14011412.

12. Guazelli, C. F., Fattori, V., Colombo, B. B., Georgetti, S. R., Vicentini, F. T., Casagrande, R., ... \& Verri Jr, W. A. (2013). Quercetin-loaded microcapsules ameliorate experimental colitis in mice by anti-inflammatory and antioxidant mechanisms. Journal of Natural Products, 76(2): 200-208.

13. Gupta, S., Chauhan, D., Mehla, K., Sood, P., \& Nair, A. (2010). An overview of nutraceuticals: current scenario. Journal of basic and clinical pharmacy, 1(2): 55.

14. Holub, B. J. (2002). Clinical nutrition: 4. Omega-3 fatty acids in cardiovascular care. Canadian Medical Association Journal, 166(5): 608-615.

15. Jakribettu, R. P., Boloor, R., Bhat, H. P., Thaliath, A., Haniadka, R., Rai, M. P., ...\& Baliga, M. S. (2016). Ginger (ZingiberofficinaleRosc.) Oils.In Essential Oils in Food Preservation, Flavor and Safety, 447-454.

16. Kalra, E. K. (2003). Nutraceutical-definition and introduction. Aaps Pharmsci, 5(3): 27-28.

17. Kini, U., \& Nandeesh, B. N. (2012). Physiology of bone formation, remodeling, and metabolism. In Radionuclide and hybrid bone imaging (pp. 2957). Springer, Berlin, Heidelberg.

18. Klatte, E. T., Scharre, D. W., Nagaraja, H. N., Davis, R. A., \&Beversdorf, D. Q. (2003). Combination therapy of donepezil and vitamin $\mathrm{E}$ in Alzheimer disease. Alzheimer Disease \& Associated Disorders, 17(2): 113-116.

19. Kochhar, K. P. (2008). Dietary spices in health and diseases: I. Indian Journal Physiol Pharmacol, 52(2): 106-122.

20. Kumar, K., \& Kumar, S. (2015). Role of nutraceuticals in health and disease prevention: a review. South Asian Journal Food Technol Environ, 1: 116-121.

21. Kumar, P., Kumar, N., \& Omer, T. (2016).A review on nutraceuticals-critical supplement for building a healthyworld. World journal of pharmacy and pharmaceutical sciences, 5(3): 57994.

22. Li, S. Q., \& Zhang, Q. H. (2001).Advances in the development of functional foods from buckwheat. Critical reviews in food science and nutrition, 41(6): 451-464.

23. Macfarlane, S. M. G. T., Macfarlane, G. T., \& Cummings, J. T. (2006). Prebiotics in the gastrointestinal tract. Alimentary pharmacology \& therapeutics, 24(5): 701-714.

24. Patel, C. N., Shah, N., \& Anand, I. S. (2006). Probiotic, prebiotic and symbiotic. The Indian Pharmacist, 5(47): 20-24.

25. Peralta, A. M. S. (2016). Vitamins in Diets: Metabolism Relationship. Global Journal of Pharmaceutical Education and Research, 1(2): 50-60.

26. Pludowski, P., Holick, M. F., Grant, W. B., Konstantynowicz, J., Mascarenhas, M. R., Haq, A., ... \& Rudenka, E. (2018). Vitamin D supplementation guidelines. The Journal of steroid biochemistry and molecular biology, 175, 125135.

27. Sapkale, A. P., Thorat, M. S., Vir, P. R., \& Singh, M. C. (2012). Nutraceuticalglobal status and applications: A review. Int J Pharm Clin Sci, 1, 1166-81.

28. Sęczyk, Ł., Świeca, M., Gawlik-Dziki, U., Luty, M., \& Czyż, J. (2016). Effect of fortification with parsley (Petroselinum crispum Mill.) leaves on the nutraceutical and nutritional quality of wheat pasta. Food chemistry, 190, 419-428.

29. Seo, T., Blaner, W. S., \& Deckelbaum, R. J. (2005). Omega-3 fatty acids: molecular approaches to optimal biological outcomes. Current opinion in lipidology, 16(1): $11-18$.

30. Serrano, A., Ros, G., \& Nieto, G. (2018). Bioactive compounds and extracts from traditional herbs and their potential anti-inflammatory health effects. Medicines, 5(3), 76.

31. Shahidi, F. (2012). Nutraceuticals, functional foods and dietary supplements in health and disease. Journal of Food and Drug Analysis, 20(1): 226-230.

32. Shara, M., \& Stohs, S. J. (2015). Efficacy and safety of white willow bark (Salix alba) 
extracts. Phytotherapy Research,29(8): 11121116.

33. Singh, J., \& Sinha, S. (2012). Classification, regulatory acts and applications of nutraceuticals for health. International Journal of Pharma and Bio Sciences, 2, 177-187.

34. Singh, J., Ancheria, R. K., Khinchi, M. P., Nama, N., \& Singh, S. P. (2017). A Review on Food Supplement-Nutraceuticals. Asian Journal of Pharmaceutical Research and Development, 1-7.

35. Singh, V., Mahaur, S., \&Kushwaha, S. K. (2018). Nutraceuticals: A New Golden Era in Health and Disease. Asian Journal of Research in Chemistry, 11(3): 652-658.

36. Smolskaite, L., Venskutonis, P. R., \& Talou, T. (2015). Comprehensive evaluation of antioxidant and antimicrobial properties of different mushroom species. LWT-Food Science and Technology, 60(1): 462-471.

37. Singh, J., Ancheria, R. K., Khinchi, M. P., Nama, N., \& Singh, S. P. (2017). A Review on Food Supplement-Nutraceuticals. Asian Journal of Pharmaceutical Research and Development, 1-7.

38. Steiner, M., Khan, A. H., Holbert, D., \& Lin, R. I. (1996).A double-blind crossover study in moderately hypercholesterolemic men that compared the effect of aged garlic extract and placebo administration on blood lipids. The American journal of clinical nutrition, 64(6): 866870.
39. Suvarna, V. C., \& Boby, V. U. (2005). Probiotics in human health: A current assessment. Current science, 88(11): 1744-1748.

40. Telang, P. S. (2013). Vitamin C in dermatology. Indian dermatology online journal, 4(2): 143

41. Wilson, D., Varigos, G., \& Ackland, M. L. (2006). Apoptosis may underlie the pathology of zinc-deficient skin. Immunology and cell biology, 84(1), 28-37.

42. Yang, F., Song, L., Wang, H., Wang, J., Xu, Z., \& Xing, N. (2015).Quercetin in prostate cancer: Chemotherapeutic and chemopreventive effects, mechanisms and clinical application potential. Oncology reports, 33(6): 2659-2668.

43. Chintale Ashwini, G., Kadam Vaishali, S., Sakhare Ram, S., Birajdar Ganesh, O., \& Nalwad Digambar, N. (2013). Role of nutraceuticals in various diseases: A comprehensive review. Int. J. Res. Pharm. Chem, 3, 290-299.

44. Zhang, Y., Dubey, M. K., Olsen, S. C., Zheng, J., \& Zhang, R. (2009). Comparisons of WRF/Chem simulations in Mexico City with ground-based RAMA measurements during the 2006MILAGRO. Atmospheric Chemistry and Physics, 9(11), 3777-3798.

45. Batra, P., \& Sharma, A. K. (2013). Anti-cancer potential of flavonoids: recent trends and future perspectives. 3 Biotech, 3(6), 439-459. 